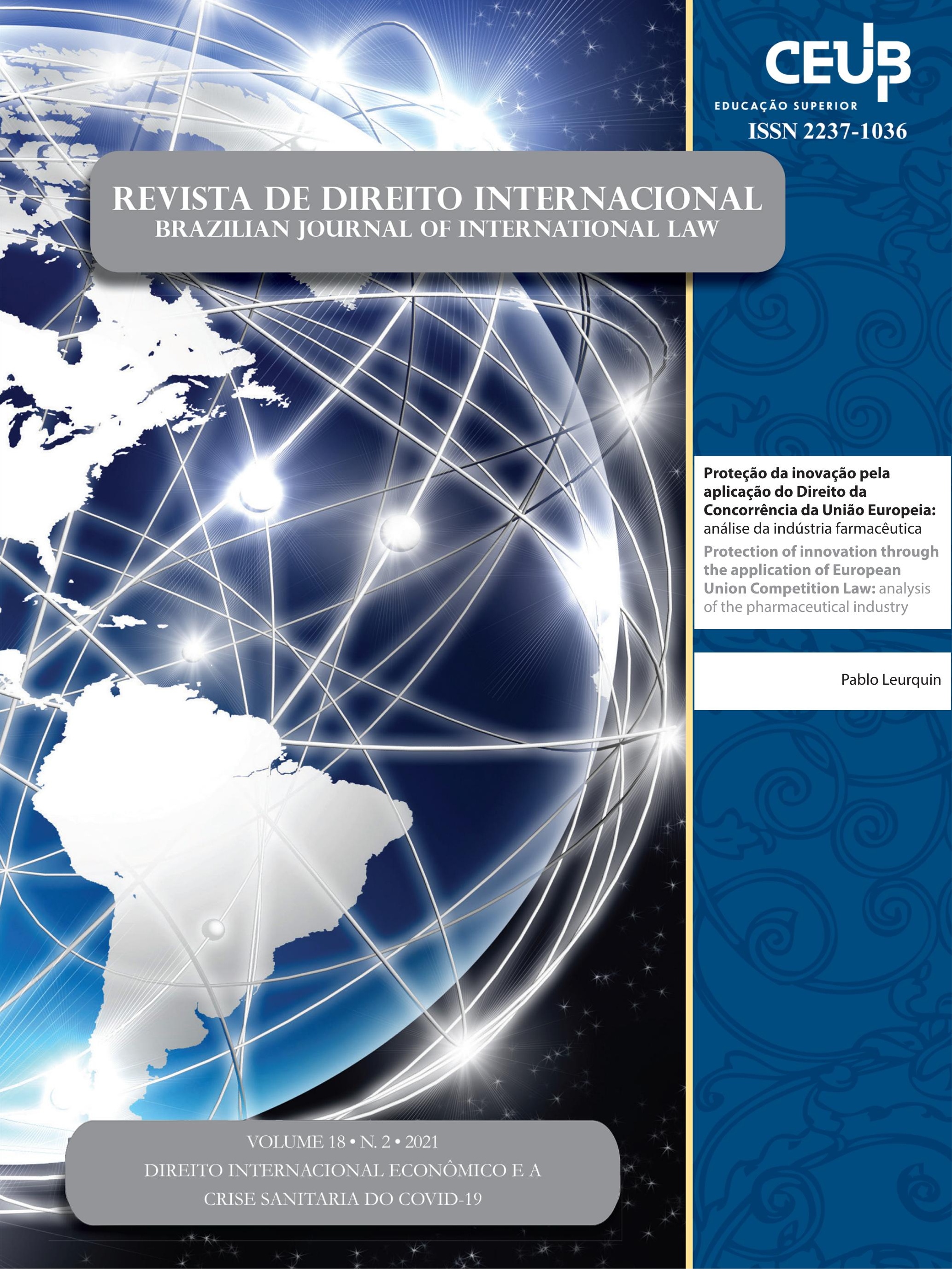




\section{Sumário}

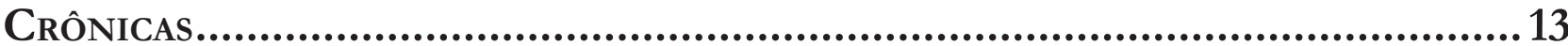

REIMAgining INTERNATIONAL RELATIONS TEACHING DURING (AND AFTER) COVID-19 ........15 Magdalena Bas

Dossiê Temático: Direito Internacional Econômico e a Crise sanitaria Do COVID-19 (INTERNATIONAL ECONOMic LaW AND THE COVID-19 SANITARY CRISIS) 19

Some QUESTIONS ABOUt INTERNATIONAL ECONOMic LAW RAISED DURING THE PANDEMIC .....21 Hervé Ascensio

International Economic LaW and the COVID-19 Sanitary Crisis: An Introduction 27 Julien Chaisse

TransparênCIA E COOPERAÇão REgUlatóRIA No COMÉRCIO INTERNACIONAL DE PRODUTOS MÉDicos PaRa a COVID-19: uMa ANÁlISE da ATUAÇão INSTITUCIONAL DA OMC E DAS NOTIFICAÇõES do Brasil EM OBSERVÂNCIA AOS ACordos TBT E SPS .35

Magali Favaretto Prieto Fernandes e Michelle Ratton Sanchez Badin

O DEVER HUMANO DE PROMOÇÃo DA SAÚDE: A AVIAÇÃo COMERCIAL INTERNACIONAL EM PERÍODOS DE CALAMIDADE SANITÁRIA E DO RETORNO À NORMALIDADE .56

Thiago de Oliveira Frizera, Luisa Cortat Simonetti Gonçalves e Adriano Sant'Ana Pedra

Police Powers Doctrine: a reliable State Defense in times of Covid-19?.... .73 Thomas Lehmann

A inexistênCia do Controle preventivo legislativo de Convencionalidade da Medida Provisória n. ${ }^{\circ} 936 / 2020$ .91

Danilo Garnica Simini, Gabriel Carvalho Moreira e Rafaela Souza Machado 
A Critical analysis of the implications of Covid-19 on piracy off the Nigerian COAST

Kalu Kingsley Anele

The COVID-19 PANDEMIC AS AN IMPELlER FOR THE AGgRAVATION OF MARINE PLASTIC POLLUTION AND ECONOMIC CRISIS: THE REVERSE EFFECT OF HEALTH PROTECTION MEASURES ON HUMAN LIVES 135

Adriana Isabelle Barbosa Lima Sá Leitão e Tarin Cristino Frota Mont’Alverne

Artigos sobre outros temas

O Direito Internacional Humanitário nos Pareceres Consultivos da Corte Internacional de Justiça: uma Conjugação de Perspectivas Utópicas e Apologéticas 156

Talis Prado Pinto Junior e Arthur Roberto Capella Giannattasio

Contesting immunities in the International Criminal Court: an analysis of the RUlings of the Pre-Trial Chambers and the Appeals Chamber in Al Bashir Case and its OUTCOMES. 171

Luisa Giannini e Roberto Vilchez Yamato

Rumo à Profissionalização da Prevenção de Controvérsias nos Acordos de CooperaÇão e Facilitação de InVEstimentos (ACFIs) do Brasil? 191

Nitish Monebhurrun e Leonardo Vieira Arruda Achtschin

THE PREVENTIVE CHARACTER OF DISASTER LAW: TAX INCENTIVES IN ENVIRONMENTAL, SOCIAL, AND GOVERNANCE (ESG) INVESTMENTS AS A RISK MITIGATION MECHANISM 212

Daniel Dela Coleta Eisaqui e Deilton Ribeiro Brasil

A URGÊNCIA DE UM MODELO DE GOVERNANÇA INTERNACIONAL DA ÁGUA: ELEMENTOS PARA A DISCUSSÃO

José Irivaldo Alves Oliveira Silva

O FIM DA HIERARQUIA SUPRALEgAL DOS TRATADOS INTERNACIONAIS: ANÁLISE DA ADI N.O 5.543/2020-DF: À luZ dA TeOria ARgumentativa de Neil Maccormick. 
Os DIREITOS HUMANOS FRENTE À NORMATIVIDADE “IMPERIAL" E A RESPONSABILIDADE DAS EMPRESAS TRANSNACIONAIS POR VIOLAÇÃO AOS DIREITOS HUMANOS NA ERA DO “IMPÉRIO” 280

Fernando Hoffmam e Jose Luis Bolzan de Morais

O RECONHECIMENTO FACIAL NAS SMART CITIES E A GARANTIA DOS DIREITOS À PRIVACIDADE E À PROTEÇÃO DE DADOS PESSOAIS.. 302

Diogo Dal Magro e Vinícius Borges Fortes

O DESENVOLVIMENTO HISTÓRICO DA PROSCRIÇÃo DO DESAPARECIMENTO FORÇADO DE PESSOAS E sua fenomenologia no Direito Penal Internacional e no Direito Internacional dos Direitos Humanos

Marcus Vinícius Xavier de Oliveira

CONSTITUCIONALISMO COOPERATIVO GLOBAL E DIREITO INTERNACIONAL PRIVADO: INSTRUMENTOS PARA UMA GOVERNANÇA DE DIREITO TRANSNACIONAL NA INTEGRAÇÃO. 362

Anderson Vichinkeski Teixeira, Roberto Correia da Silva Gomes Caldas e Luciane Klein Vieira

Proteção da inovação pela aplicaÇão do Direito da ConcorrênCia da União Europeia: ANÁLISE DA INDÚSTRIA FARMACÊUTICA.

Pablo Leurquin 


\title{
Proteção da inovação pela aplicação do Direito da Concorrência da União Europeia: análise da indústria farmacêutica*
}

\author{
Protection of innovation through the \\ application of European Union Competition \\ Law: analysis of the pharmaceutical industry
}

Pablo Leurquin**

\section{Resumo}

A oposição entre a defesa da concorrência e os direitos de propriedade intelectual, ou a abstrata complementariedade entre essas normas jurídicas, não são suficientes para resolver os desafios da interface entre esses ramos do Direito. Entende-se que esses desafios devem ser avaliados em setores específicos e em um determinado ordenamento jurídico. O objetivo deste artigo é investigar como o Direito da Concorrência da União Europeia tem sido aplicado para punir comportamentos abusivos de empresas detentoras de direitos de propriedade intelectual. A indústria farmacêutica foi selecionada para ser analisada, sobretudo, por causa da recorrente instrumentalização das patentes para excluir a entrada de genéricos no mercado. Realizouse levantamento dos principais julgados de órgãos europeus de defesa da concorrência, com intuito de avaliar as suas contribuições na proteção da inovação. Constatou-se que o modelo europeu consolidou a importância das autoridades de defesa da concorrência em casos envolvendo direitos de propriedade intelectual.

Palavras-chave: Direito da Concorrência da União Europeia; direito econômico; propriedade intelectual; proteção da inovação; indústria farmacêutica.

* Recebido em 03/05/2021 Aprovado em 21/07/2021

** Doutor em Direito pela Université Paris 1 Panthéon-Sorbonne e pela Universidade Federal de Minas Gerais, em cotutela. Mestre em Direito pela Universidade Federal de Minas Gerais. Bacharel em Direito pela Universidade Federal do Rio Grande do Norte. Professor Adjunto na Universidade Federal de Juiz de Fora - campus Governador Valadares.

E-mail: pabloleurquin@gmail.com

\section{Abstract}

The opposition between the safeguarding of competition and intellectual property rights, or the abstract complementarity of these set of legal norms, are not sufficient to solve the challenges of the interface between these branches of law. These challenges must be assessed in specific sectors and in a specific legal system. The purpose of this article is to investigate how European Union Competition Law has been applied to punish abusive behavior by companies with intellectual property rights. The pharmaceutical industry was analyzed, mainly due to the recurrent use of patents to exclude the entry of generic brands in the market. An analysis of the main judgments of European competition agencies was carried out, with the aim of evaluating their contributions to the protection of innovation. All the evi- 
dence suggests that the European model consolidated the importance of competition authorities in cases involving intellectual property rights.

Keywords: European Union Competition Law; economic law; intellectual property; protection of innovation; pharmaceutical industry.

\section{Introdução}

Os direitos de propriedade intelectual são comumente considerados como uma das técnicas jurídicas mais eficazes para incentivar o processo contínuo de inovação. Essa compreensão reforça uma questionável hegemonia no que diz respeito à proteção, quase que absoluta, da exclusividade decorrente da referida tutela jurídica. A crescente quantidade de direitos de propriedade intelectual não significa, entretanto, o aumento da inovação.

Os últimos anos têm permitido um olhar renovado sobre as consequências dos direitos de propriedade intelectual sobre a inovação ${ }^{1}$. Entre os motivos desse questionamento, está, por exemplo, a importância do paradigma open source $e^{2}$, que tem promovido inovações tão ou mais relevantes do que aquelas classicamente protegidas pelos direitos de propriedade intelectual ${ }^{3}$.

\footnotetext{
1 Sobre a relação entre o Acordo TRIPS e o fomento e difusão de inovação tecnológica, ver: SILVA, Tatianna Mello Pereira da. Acordo TRIPS: one-size-fits-all? Revista de Direito Internacional, Brasília, v. 10, n. 1, p. 57-70, 2013. Disponível em: https://www.publicacoesacademicas.uniceub.br/rdi/article/view/1987/pdf. Acesso em: 30 jul. 2021. Sobre os desdobramentos da referida proteção internacional da propriedade intelectual no desenvolvimento do Brasil, ver: SEGALA, Michele M.; GREGORI, Isabel Christine S. de. Os reflexos da proteção internacional da propriedade intelectual para o desenvolvimento interno: uma análise sobre o sistema patentário brasileiro e a transferência de tecnologia. Revista de Direito Internacional, Brasília, v. 1, n. 2, p. 524-535, 2017. Disponível em: https:// www.publicacoesacademicas.uniceub.br/rdi/article/view/4678/ pdf. Acesso em: 30 jul. 2021.

2 "As licenças open source são compreendidas como uma licença de direito do autor, associada a uma licença de patente, com o objetivo de difundir e explorar o conhecimento. Portanto, uma licença open source não constitui apenas a precisão do acesso ao códigofonte, ela representa, igualmente, um modelo sobre as condições ofertadas ao licenciado". LEURQUIN, Pablo. Proteção da inovação pelo direito da concorrência. Belo Horizonte: Expert, 2021. p. 34.

3 HILTY, Reto M. La limitation de la propriété intellectuelle comme moyen d'encourager l'innovation. In: GEIGER, Christophe; RODÀ, Caroline (coord.). Le droit de la propriété intellectuelle dans un monde globalisé: mélanges en l'honneur du Professeur Joanna Schmidt-Szalewski. Paris: Lexis Nexis, 2013. p. 201-220. p. 208.
}

Frisa-se também que direitos de propriedade intelectual têm sido utilizados como parâmetros por investidores, valorizando as ações das empresas detentoras dos ditos direitos, independentemente da comercialização dos "novos" produtos. Além disso, os direitos de propriedade intelectual também funcionam para dissuadir a entrada de novos concorrentes ${ }^{4}$. Ou seja, a gestão contemporânea da política de propriedade intelectual pode gerar distorções das mais diferentes naturezas, entre as quais está também as de dimensão concorrencial.

Existe uma narrativa amplamente difundida de que o Direito da Concorrência não deve intervir em casos que envolvam os ditos direitos. As exceções desse entendimento costumam seguir a linha de argumentação da teoria das infraestruturas essenciais. Essa teoria foi formulada com base nos problemas com o acesso à infraestrutura ferroviária nos EUA, no início do século XX. A aplicação dessa construção permite identificar se um detentor de um determinado recurso deve garantir o acesso a seus concorrentes, no caso desse recurso ser indispensável a estes para o exercício de sua atividade ${ }^{5}$.

Apesar de se reconhecer a importância da Teoria das Infraestruturas Essenciais, a sua aplicação no campo dos direitos de propriedade intelectual é polêmica. Ademais, há relevante divergência quanto à incorporação da dita teoria no Direito da Concorrência da União Europeia, uma vez que, nesses tipos de casos, utilizam-se outras construções teóricas e jurisprudenciais. Um exemplo desses outros percursos argumentativos foi a condenação da Microsoft, em 2007, que ocorreu ancorada nos efeitos anticoncorrenciais da recusa de contratar e da venda casada ${ }^{6}$.

O objetivo deste artigo é investigar como o Direito da Concorrência da União Europeia tem sido aplicado para revelar comportamentos abusivos de empresas detentoras de direitos de propriedade intelectual. Para

4 DOSI, Giovani; MARENGO, Luigi; PASQUALI, Corrado. How much should society fuel the greed of innovators? On the relations between appropriability, opportunities and rates of innovation. Research Policy, v. 35, n. 8, p. 1110-1121, 2006. Disponível em: https:// www.econstor.eu/bitstream/10419/89527/1/51846122X.pdf. Acesso em: 01 jun. 2019. p. 1115.

5 DEZOBRY, Guillaume. Facilités essentielles. In: BAZEX, Michel et al. (dir.). Dictionnaire des régulations. Paris: Lexis Nexis, 2016. p. 330. 6 Para uma análise da decisão do caso Microsoft, ver: LEURQUIN, Pablo. A importância do caso Microsoft na modernização do Direito da Concorrência da União Europeia. In: ARAÚJO, Francisco Marcos de; SALDANHA, Ana Clara Bezerra de Góis; AMARAL, Maria Teodora Rocha Maia (orgs.). O direito e as novas tecnologias na sociedade da informação. São Paulo: Dialética, 2021. No prelo. 
escapar dos argumentos abstratos de complementariedade ou oposição desses ramos do direito, optou-se por analisar apenas o setor farmacêutico. A investigação se ancorou nas decisões das autoridades da União Europeia e da Autorité de la Concurrence, órgão francês responsável pela defesa da concorrência. Pretende-se, assim, explorar as peculiaridades do modelo europeu, demonstrando que este tem sido aplicado sem obrigatoriamente recorrer à teoria norte-americana das infraestruturas essenciais.

As reiteradas condenações de empresas na indústria farmacêutica também chamam atenção por ser um setor no qual incide uma série de normas jurídicas decorrentes da regulação econômica setorial, de direitos de propriedade intelectual e de Direito da Concorrência. Essas intervenções concorrenciais exploradas, nos casos selecionados, tratam de empresas detentoras de patentes de medicamentos que agiram para dificultar ou impedir a entrada de seus genéricos nos mercados. Para alcançar o objetivo do presente artigo, este foi dividido em quatro seções.

Na primeira seção, o papel do Direito da Concorrência da União Europeia para a proteção da inovação será elucidado com base na modernização das referidas normas, que ocorreu em duas etapas. A primeira, em 2003, relativa ao domínio do controle dos acordos, com o Regulamento n. 1/2003 do Conselho da União Europeia. A segunda, relativa ao domínio das práticas unilaterais, com orientações de 2009, da Comissão Europeia para aplicação do art. 82, do Tratado das Comunidades Europeias (atual art. 102). Esses dois momentos representaram a consolidação de uma abordagem ancorada na tradição europeia, mas atualizada com os aportes da Economia Industrial contemporânea. As duas etapas de modernização reforçaram o papel da proteção da inovação e esta passou a ser ainda maior em relação à intervenção concorrencial ${ }^{7}$.

Nas segunda e terceira seções, as decisões do Tribunal de Justiça da União Europeia (TJUE), no caso AstraZeneca e Servier, serão respectivamente analisadas. Essas condenações evidenciam as limitações das autoridades responsáveis por conceder direitos de proprieda-

LEURQUIN, Pablo. Proteção da inovação pelo direito brasileiro da concorrência e diálogo com o direito da União Europeia. 2018. Tese (Doutorado em Direito) - Universidade Federal de Minas Gerais, Belo Horizonte; Université Paris 1 Panthéon-Sorbonne, Paris, 2018. de intelectual para a avaliação da instrumentalização dos ditos direitos para finalidades anticoncorrenciais.

$\mathrm{Na}$ quarta seção, a decisão da Autoridade da Concorrência francesa no caso Buprenorfina será examinada. Frisa-se que o referido órgão não é propriamente do Direito da União Europeia. Entretanto, a escolha desse julgado se justifica por representar um avanço do paradigma adotado com base na modernização, indo além da própria Comissão da União Europeia ao condenar utilizar o Direito da Concorrência para punir a depreciação de concorrentes.

\section{Papel do Direito da Concorrência da União Europeia para a proteção da inovação}

A integridade do mercado interno europeu é um elemento central no pacto jurídico-político da União Europeia $^{8}$. O Tratado sobre o Funcionamento da União Europeia (TFUE) dedica título específico, na parte que versa acerca das políticas e ações internas da União Europeia, para abordar o tema do mercado interno, que é conceituado como "um espaço sem fronteiras internas no qual a livre circulação das mercadorias, das pessoas, dos serviços e dos capitais é assegurada de acordo com as disposições dos Tratados" (art. 26, $2^{\circ}$ ). Conforme dispõe o referido dispositivo, é de competência da União Europeia adotar "as medias destinadas a estabelecer o mercado interno ou a assegurar o seu funcionamento" $\left(\operatorname{art.} 26,1^{\circ}\right)$.

Essa compreensão jurídica do mercado permite entender que este não é visto como uma ordem natural da economia, considerando-se que o Direito tem especial relevância para a concepção e a proteção de suas finalidades públicas e privadas. Importa frisar, também, que o modelo europeu não entende a concorrência como um fim em si mesmo. Ou seja, a aplicação do Direito da Concorrência admite outras considerações de interesse público e voltadas à promoção de direitos fundamen-

\footnotetext{
8 Para uma análise da teoria jurídica da integração regional e da experiência da União Europeia, ver: DIZ, Jamile Bergamaschine Mata; JAEGER JÚNIOR, Augusto. Por uma teoria jurídica da integração regional: a inter-relação direito interno, direito internacional público e direito da integração. Revista de Direito Internacional, Brasília, v. 12, n. 2, p. 138-158, 2015. Disponível em: https://www.publicacoesacademicas.uniceub.br/rdi/article/view/3710/pdf. Acesso em: 30 jul. 2021.
} 
tais 9 . É importante destacar que as normas de Direito da Concorrência da União Europeia têm como finalidade o fortalecimento do próprio mercado interno europeu. Portanto, o art. 101 e seguintes tratam das regras comuns de concorrência, estabelecendo os parâmetros para avaliação da compatibilidade dos atos das empresas com o próprio mercado interno.

A modernização mais recente do Direito da Concorrência da União Europeia procurou responder determinadas críticas ao modelo europeu, especialmente no que diz respeito ao fato de ele ser demasiadamente formalista. Para tanto, foram incorporados alguns aportes da Economia Industrial contemporânea, mas sem perder de vista a própria tradição jurídico-política do Direito da União Europeia.

As origens da Economia Industrial (Industrial Organization) remontam a uma tradição inaugurada com os trabalhos dos "engenheiros-economistas" Antoine Augustin Cournot e Jules Dupuit. Em seguida, essa teoria foi desenvolvida pela aplicação do Sherman Act e legislações seguintes. Esse ramo da economia ganhou nova força com o modelo da Escola de Harvard de "Estrutura-Conduta-Desempenho", que se filia à tradição iniciada por Joe Bain, posteriormente desenvolvida por F. M. Scherer. Sua forte influência na formulação da política concorrencial estadunidense durou até a ascensão da Escola de Chicago, em meados da década de 1970, a qual manteve sua hegemonia até a crise de $2008^{10}$.

Um dos maiores expoentes da Economia Industrial contemporânea é o economista francês Jean Tirole, vencedor do Prêmio Nobel de Economia, alcançado em 2014. Ele contribuiu, significativamente, para a reformulação da atuação das autoridades concorrenciais europeias, especialmente em casos envolvendo acordos verticais; colusão tácita e coordenada; concentrações horizontais; mercados de dois lados e plataformas de intermediação; e patentes e suas interseções com concorrência. Esses aportes teóricos permitiram que as autoridades europeias lançassem um olhar crítico às estratégias dos novos monopólios da Economia da Infor-

\footnotetext{
9 IDOT, Laurence. Réflexions sur la convergence des droits de la concurrence. Concurrences, n. 4, 2012. p. 167.

10 Para uma análise da relação entre a Economia Industrial contemporânea, também chamada de Nova Economia Industrial, e o Movimento Pós-Chicago no Direito da Concorrência: LEURQUIN, Pablo. Proteção da inovação pelo direito da concorrência. Belo Horizonte: Expert, 2021. p. 219 e s.
}

mação e de empresas detentoras de direitos de propriedade intelectual, notadamente no setor farmacêutico ${ }^{11}$.

Uma das principais contribuições da modernização do Direito da Concorrência da União Europeia foi a renovada importância dada à punição de estratégias de empresas que tentam manter artificialmente sua posição no mercado, considerando-se que colocou a proteção da inovação dos concorrentes no centro da análise. A referida modernização também permitiu um novo olhar sob a abusividade de estratégias comerciais e de exercício de direitos de propriedade intelectual, muitas vezes vistos como inofensivos ou mesmo parte da própria dinâmica concorrência. Em decorrência desse processo, percebe-se uma relevante originalidade da perspectiva europeia sobre a importância da aplicação do Direito da Concorrência para a consolidação de estruturas econômicas conducentes à inovação ${ }^{12}$.

A originalidade dessa experiência somente pode ser compreendida se o modelo europeu for comparado sucintamente com o norte-americano. Convém destacar que a disputa entre o modelo europeu e estadunidense percorre diversos temas no Direito da Concorrência, entre os quais, está a definição do papel do Estado no combate às práticas anticoncorrenciais. A trajetória da aplicação do Antitrust Law estadunidense, sobretudo sob a influência da Escola de Chicago, consolidou uma tendência de impunidade de empresas em posição dominante que põem em prática estratégias para excluir seus competidores. De acordo com Joseph Stiglitz:

a influência da Escola de Chicago não pode ser
subestimada. Mesmo quando existem infrações ób-
vias - como as predatórias atribuições de preços,
em que uma empresa baixa os seus preços para ex-
pulsar um concorrente, e depois usa esse poder de
monopólio para tornar a aumentar os preços -, elas
são difíceis de processar. A economia da Escola de
Chicago defende que os mercados são supostamen-
te competitivos e eficientes. Se a entrada nos merca-
dos fosse fácil, a empresa dominante não ganharia
nada em afastar uma rival, uma vez que a empresa

11 LEURQUIN, Pablo. Proteção da inovação pelo direito brasileiro da concorrência e diálogo com o direito da União Europeia. 2018. Tese (Doutorado em Direito) - Universidade Federal de Minas Gerais, Belo Horizonte; Université Paris 1 Panthéon-Sorbonne, Paris, 2018. p. 167 e s. 12 Sobre a modernização do Direito da Concorrência da União Europeia, com especial ênfase na importância renovada dada à teoria dos efeitos, ver: JAEGER JÚNIOR, Augusto; JORGE, Mariana Sebalhos. O caso interl: o impacto na evolução da teoria dos efeitos no direito da concorrência da União Europeia. Revista de Direito Internacional, Brasília, v. 16, n. 1, p. 269-287, 2019. Disponível em: https:// www.publicacoesacademicas.uniceub.br/rdi/article/view/5655/ pdf. Acesso em: 30 jul. 2021. 
afastada seria rapidamente substituída por outra. Porém, na realidade, a entrada não é assim tão fácil, e é um facto que os comportamentos predatórios são frequentes ${ }^{13}$.

O modelo norte-americano tem se caracterizado pela maior liberdade às empresas em posição dominante, com base no entendimento segundo o qual esses agentes econômicos estariam mais próximos aos interesses dos consumidores, e uma intervenção concorrencial desencorajaria investimentos e inovações ${ }^{14}$. O modelo europeu, por sua vez, tem como uma das principais características a consolidada intervenção no eixo das práticas anticoncorrenciais, também conhecidas como abusos de posição dominante ${ }^{15}$. Essa tendência vem se consolidando ao longo dos anos, especialmente, a partir da condenação da Microsoft, em 2007, mas remete a decisões proferidas ao longo da década de $1970^{16}$.

No que diz respeito aos direitos de propriedade intelectual, cumpre ressaltar que determinadas práticas abusivas foram facilitadas pela queda na qualidade das patentes, decorrência da multiplicação/proliferação de pedidos para o seu reconhecimento. As autoridades responsáveis pelo exame das patentes têm se mostrado incapazes de avaliar com precisão todas as demandas, o que significou um relaxamento da concessão da proteção patentária ${ }^{17}$. As empresas, por sua vez, utilizam-se dessa situação para fazer requerimentos infundados com único objetivo de prolongar ilicitamente a sua condição de monopolista. Entre os exemplos da utilização anticoncorrencial de direitos de propriedade intelectual, podem-se destacar os casos de trivial patent, frivolous pa-

13 STIGLITZ, Joseph E. O preço da desigualdade. Lisboa: Bertrand Editor, 2013. p. 109.

14 FOX, Eleanor. Economic development, poverty, and antitrust: the other path. Southwestern Journal of Law and Trade in the Americas, v. 13, p. 101-125, 2007. Disponível em: https://papers.ssrn.com/sol3/ papers.cfm?abstract_id=1002637. Acesso em: 16 abr. 2018. p. 117.

15 Sobre a comparação entre a tradição norte-americana e a europeia no campo da aplicação do Direito da Concorrência nos acordos horizontais e verticais, ver: FERRAZ, Daniel Amin. A jurisprudência norteamericana e europeia sobre os acordos horizontais e verticais: substrato para análise da matéria no Brasil. Revista de Direito Internacional, Brasília, v. 10, n. 1, p. 232-242, 2013. Disponível em: https://www.publicacoesacademicas.uniceub.br/rdi/article/ view/2427/pdf. Acesso em: 30 jul. 2021.

16 PRIETO, Catherine; BOSCO, David. Droit européen de la concurrence: ententes et abus de position dominante. Bruxelas: Bruylant, 2013. p. 1-2.

17 KOVAR, Robert. Les innovations abusives: à la croisée des droits de propriété intellectuelle et de la concurrence. Droits de propriété intellectuelle: liber amicorum Georges Bonet. Paris: Lexis Nexis Litec, 2010. p. 315-317. tent, patent ambush, patent thicket, submarine patent, patent hold up e patent evergreening. Essas expressões revelam que há um crescimento incontestável de utilização de direitos de propriedade intelectual com finalidade anticoncorrencial.

Além dessas observações, as constatações feitas permitem lançar um novo olhar em diversas indústrias, sobretudo na farmacêutica e na de tecnologias de informação e comunicação. O ponto em comum entre esses setores é a verificação de que determinadas empresas atuantes nessas áreas têm posto em prática estratégias para desestimular o processo contínuo de inovação. Essa constatação leva ao questionamento, de natureza geral, sobre o limite da liberdade do agente econômico, atuante em um monopólio ou oligopólio. Em termos mais específicos, trata-se de refletir acerca da definição de uma política concorrencial que combata a manutenção artificial do poder de mercado, com base na exclusão da possibilidade de competidores oferecerem produtos, serviços ou tecnologias mais relevantes ou mais baratos.

Esses argumentos têm um ponto em comum: a necessária ressignificação do papel da inovação na aplicação do Direito da Concorrência. Entende-se, no mesmo sentido de Tim $\mathrm{Wu}^{18}$, que essa reinterpretação significa dar maior relevância às práticas anticoncorrenciais, especialmente àquelas exclusionárias, considerando-se a potencialidade dos danos à concorrência dinâmica. Essa interpretação alinha-se ao que sustenta Luis Fernando Schuartz:

num sentido normativamente relevante, então, a "defesa" institucional da concorrência vai orientar as suas ações para a criação e a reprodução de um ambiente competitivo no qual as referidas pressões atuantes sobre os agentes (e os seus mercados) sejam mantidas num nível que permita presumir que o motor efetivo daquele processo dinâmico em que assimetrias competitivas são criadas, estabilizadas, incrementadas ou neutralizadas (como resultado natural do processo de valorização do capital) está na introdução de inovações, e que o efeito colateral mais importante deste processo dinâmico está numa rápida e ampla difusão dos ganhos de eficiência associados a estas inovações ${ }^{19}$.

18 WU, Tim. Taking innovation seriously: antitrust enforcement if innovation mattered most. Antitrust Law Journal, Washington, v. 78, n. 2, 2012. Disponível em: https://scholarship.law.columbia.edu/ faculty_scholarship/1767/. Acesso em: 20 dez. 2019. p. 317.

19 SCHUARTZ, Luis Fernando. O direito da concorrência e seus fundamentos. In: POSSAS, Mario Luiz (coord.). Ensaios sobre economia e direito da concorrência. São Paulo: Singular, 2002. p. 33-74. p. 51. 
O Direito da Concorrência da União Europeia tem sido aplicado para descortinar a abusividade da utilização de regras de direitos de propriedade intelectual no mercado farmacêutico, por exemplo. A pluralidade de instrumentos jurídicos para a promoção da inovação e a incidência de regras de direito de propriedade intelectual dão complexidade especial à aplicação das normas concorrenciais no setor em questão. Esse contexto toma outras proporções com a ascensão e relevância dos medicamentos genéricos, conforme será visto adiante.

\section{Decisão do caso Astrazeneca}

A decisão do TJUE no caso AstraZeneca, grupo anglo-sueco do setor farmacêutico, avaliou as estratégias da empresa para impedir a entrada de genéricos do "Losec" (Omeprazol). O referido medicamento é utilizado no tratamento de pacientes com problemas de úlcera gástricas e duodenais e refluxo gastroesofágico. No que diz respeito à condenação, foi aplicada multa de 60 milhões de euros ao referido grupo por ter utilizado, de maneira abusiva, o sistema de patentes e os procedimentos de comercialização de produtos farmacêuticos ${ }^{20}$.

A empresa foi condenada por duas práticas distintas, que se inserem na estratégia global de criar barreiras artificiais à entrada de concorrentes no mercado em questão. A primeira prática foi a utilização de informações enganosas com a finalidade de prolongar, abusivamente, a proteção dos direitos de propriedade intelectual. A segunda foi o lançamento de suposto novo produto, que tinha as mesmas propriedades do antigo, sem justificação objetiva da AstraZeneca. Em outras palavras, o grupo pretendia estender ilegalmente a exclusividade na comercialização do Losec.

O mercado em questão é caracterizado por uma complexa interface entre várias técnicas jurídicas de promoção da inovação. Portanto, faz-se necessária a compreensão do contexto legal que envolve a decisão,

\footnotetext{
20 SIBONY, Anne-Lise. Définition du marché pertinent - utilisation abusive - Procédures relatives aux certificats complémentaires de protection pour les médicaments - procédures d'autorisation de mise sur le marché: la Cour de Justice de l'UE sanctionne définitivement l'utilisation abusive de procédures réglementaires pour prévenir ou retarder l'arrivée des génériques sur le marché (CJUE, 6 décembre 2012, AstraZeneca AB et AstraZeneca c/ Commission, aff. C-457/10 P). Concurrences, n. 1, p. 78-81, 2013. p. 78.
}

sobretudo, no que diz respeito às questões de regulação setorial (3.1). Em seguida, busca-se analisar como o TJUE analisou cada uma das práticas anticoncorrenciais, a saber as declarações enganosas (3.2) e a retirada das capsulas Losec do mercado (3.3).

\subsection{Incidência de várias técnicas de promoção da inovação}

A decisão do TJUE teve que respeitar um contexto jurídico caracterizado por muitas técnicas distintas de promoção da inovação, notadamente os direitos de propriedade intelectual, as normas de regulação setorial e o próprio Direito da Concorrência. O principal desafio desse caso era proteger a possibilidade da entrada dos genéricos no mercado e seus consequentes benefícios aos consumidores, sem perder de vista o necessário respeito às regras de direito de propriedade intelectual.

A importância dos direitos de propriedade intelectual para a promoção da inovação é largamente exposta na literatura científico-jurídica e econômica. Há significativa convergência entre os estudiosos do assunto sobre a sua importância para a inovação na indústria farmacêutica. A argumentação clássica parte da necessidade de se conferir exclusividade na comercialização de determinado produto à empresa que detém direitos de propriedade intelectual. Com isso, essa empresa poderá lucrar com os resultados dos investimentos realizados. Os objetivos são três: i) manter a empresa inovadora estimulada a fazer novos investimentos em outras inovações; e ii) desestimular que outras empresas tenham comportamentos parasitários, buscando usufruir indevidamente dos investimentos realizados pelo agente econômico inovador; e iii) permitir que, após o período de proteção conferida pelo direito de propriedade intelectual, o conhecimento inovador seja disponibilizado de maneira pública, permitindo que demais interessados possam replicar aquele conhecimento.

Quando se trata de um medicamento, além da concessão da patente, exige-se, na União Europeia, a $\mathrm{Au}$ torização de Introdução no Mercado (AIM). Não se pretende aprofundar nas normas e procedimento para a emissão dessa autorização, mas importa frisar que incide sobre a mesma um conjunto de requisitos estabelecidos pelo Direito da União Europeia. Esse conjunto de normas pode ser entendido como uma dimensão regulatória que contribui no fortalecimento do Mercado Comum Europeu, pois permite que medicamentos 
produzidos em determinados países possam ser comercializados em outros membros da União Europeia.

O Certificado Complementar de Proteção (CCP), por sua vez, foi criado para adicionar uma duração suplementar de proteção da patente dos medicamentos, respeitando os critérios do regulamento n. 1768/92 do Conselho das Comunidades Europeias que trata da criação do Certificado Complementar de Proteção para os medicamentos. $\mathrm{O}$ referido regulamento se insere no contexto de harmonização das condições para emitir a extensão da duração das patentes nos membros da União Europeia ${ }^{21}$. De acordo com o art. $3^{\circ}$ do regulamento:

o certificado é concedido se no Estado-Membro onde for apresentado o pedido previsto no artigo 7.o e à data de tal pedido:

a) $\mathrm{O}$ produto estiver protegido por uma patente de base em vigor;

b) O produto tiver obtido, enquanto medicamento, uma autorização válida de introdução no mercado, nos termos do disposto na Directiva 2001/83/CE ou na Directiva 2001/82/CE, conforme o caso;

c) O produto não tiver sido já objecto de um certificado;

d) A autorização referida na alínea b) for a primeira autorização de introdução do produto no mercado, como medicamento.

A técnica do CCP veio para prolongar o tempo de proteção patentária de determinados medicamentos, considerando-se que o processo de AIM era muito longo. Portanto, o CCP permite que seus beneficiários façam obstáculo à entrada de produtos concorrentes. O objetivo da criação desse certificado é beneficiar empresas que já inovaram no setor. Entretanto, a duração dessa proteção deve ser limitada, de maneira a consolidar um compromisso entre o interesse de promover a inovação e o de preservar a concorrência ${ }^{22}$.

É nesse contexto que está inserida a decisão do TJUE. Ou seja, o órgão europeu não teve como obje-

\footnotetext{
21 AHNER, Francis. La Cour de Justice au diapason? L'interprétation du règlement (CE) n. 469/2009 concernant le certificat complémentaire de protection pour les médicaments par la Cour de Justice de l'Union Européenne. In: GEIGER, Christophe; RODÀ, Caroline (coord.). Le droit de la propriété intellectuelle dans un monde globalisé: mélanges en l'honneur du Professeur Joanna Schmidt-Szalewski. Paris: Lexis Nexis, 2013. p. 1-16.

22 KOVAR, Robert. Les innovations abusives: à la croisée des droits de propriété intellectuelle et de la concurrence. Droits de propriété intellectuelle: liber amicorum Georges Bonet. Paris: Lexis Nexis Litec, 2010.
}

tivo colocar em questão os instrumentos clássicos de proteção da inovação, ou seja, as patentes. Entretanto, AstraZeneca é uma empresa em posição dominante, e isso the impõe uma responsabilidade especial de não atentar à concorrência. Essa é a justificativa jurídica central da incidência do Direito da Concorrência da União Europeia sobre suas práticas.

\subsection{Declarações enganosas}

A AstraZeneca comunicou aos institutos de patentes na Bélgica, na Dinamarca, na Alemanha, na Irlanda, em Luxemburgo, nos Países Baixos e no Reino Unido que a primeira AIM foi em março de 1988. No entanto, já existia uma AIM concedida na França no dia 15 de abril de 1987. A questão da data é importante porque ela vinculava a concessão de ampliação do tempo de vigência de proteção de patentes, por intermédio de um CCP. De acordo com o art. 19, do parágrafo $1^{\circ}$ das disposições transitórias do Regulamento n. 1768/92 do Conselho das Comunidades Europeias de 18 de junho de 1992:

\begin{abstract}
pode ser concedido um certificado para qualquer produto que, à data da adesão, esteja protegido por uma patente e para o qual tenha sido obtida uma primeira autorização de colocação no mercado na Comunidade ou nos territórios da Áustria, da Finlândia ou da Suécia, após $1^{\circ}$ de janeiro de 1985.

No que respeita aos certificados a conceder na Dinamarca, na Alemanha e na Finlândia, a data de $1^{\circ}$ de janeiro de 1985 é substituída pela data de $1^{\circ}$ de janeiro de 1988.
\end{abstract}

No que respeita aos certificados a conceder na Bélgica, na Itália e na Áustria, a data de $1^{\circ}$ de janeiro de 1985 é substituída pela data de $1^{\circ}$ de janeiro de $1982^{23}$.

O excerto acima permite compreender que a AIM, obtida antes do $1^{\circ}$ de janeiro de 1988 , não permitiria a emissão de CCP na Dinamarca, Alemanha e Finlândia. Dessa maneira, a AstraZeneca não teria sua proteção patentária estendida, caso a data da concessão da AIM na França fosse considerada. O TJUE entendeu, portanto, que referida empresa informou as datas erradas com intuito de se beneficiar ilegalmente do CCP.

23 CONSELHO DAS COMUNIDADES EUROPEIAS. Regulamento (CEE) n. 1768/92 do Conselho de 18 de junho de 1992 relativo à criação de um certificado complementar de proteção para medicamentos. Jornal Oficial das Comunidades Europeias, 18 jun. 1992. Disponível em: https://eur-lex.europa.eu/legal-content/PT/TXT/ PDF/?uri=CELEX:31992R1768\&from=PT. Acesso em: $20 \mathrm{dez}$. 2019. 
O TJUE estabeleceu que o abuso concorrencial ocorreu quando as declarações destinadas a obter, de forma irregular, direitos exclusivos levaram as autoridades públicas a conceder o direito exclusivo pedido. De acordo com o TJUE,

\begin{abstract}
[...] ao transmitir declarações enganosas a esses institutos de patentes, dissimulando a existência da referida autorização técnica francesa e deixando-os acreditar, deliberadamente, que a data de 21 de março de 1988 correspondia à autorização técnica luxemburguesa e que esta constituía a primeira AIM na Comunidade, o AZ (AstraZeneca) aceitou conscientemente que estes lhe estavam a conceder CCP que não teriam emitido se tivessem sabido da existência da autorização técnica francesa e que seriam considerados ilegais no caso de a interpretação alternativa do AZ não ser seguida pelos órgãos jurisdicionais nacionais ou pelo Tribunal de Justiça ${ }^{24}$.
\end{abstract}

Portanto, os CCP foram concedidos baseados em declarações errôneas. Em decorrência dessa estratégia de má-fé da empresa AstraZeneca, a estrutura de mercado e a concorrência potencial foram afetadas. Dessa maneira, mesmo que esse comportamento tenha sido infrutífero em certos países, eles tinham grande potencial de gerar emissões de CCP irregulares.

O TJUE também ressaltou, na linha da argumentação da Comissão Europeia, que esse comportamento deve ser compreendido como parte de uma estratégia global de manter os fabricantes de genéricos indevidamente excluídos do mercado. Para entender essa compreensão do TJUE, analisaram-se os efeitos concorrenciais da estratégia comercial da empresa ao retirar as cápsulas de Losec do mercado.

\subsection{Retirada das cápsulas de Losec do mercado}

O TJUE entendeu que a retirada das cápsulas de Losec do mercado da Dinamarca, Suécia e Noruega configurou o segundo abuso de posição dominante. Essa retirada ocorreu após expiração do direito exclusivo de explorar os resultados dos testes farmacológicos, toxicológicos e clínicos, que são reconhecidos pela Diretiva do Conselho da Comunidade Econômica Europeia n. 65 de 26 de janeiro de 1965. Com o fim da exclusividade da comercialização do medicamento, a AstraZeneca

\footnotetext{
24 TRIBUNAL DE JUSTIÇA DA UNIÃO EUROPEIA. Processo n. C-457/10P, AstraZeneca/Comissão, 6 déc. 2012. Disponível em: http://curia.europa.eu/juris/document/document.jsf?text=\&doci $\mathrm{d}=131490$ \&pageIndex $=0 \&$ doclang $=$ PT\&mode $=1$ st\&dir $=\& o c c=$ fir st\&part $=1 \&$ cid $=342734$. Acesso em: 20 dez. 2019.
}

retirou o medicamento do mercado e lançou um novo, o Losec MUPS.

Essa estratégia tinha como objetivo renovar a exclusividade na comercialização do medicamento, na tentativa de impedir a competição dos genéricos. De acordo com o TJUE:

a este respeito, importa, nomeadamente, constatar,
como o Tribunal Geral sublinhou no n. ${ }^{\circ} 675$ desse
acórdão, que, após o termo do período de exclusi-
vidade acima referido, o comportamento que, inter
alia, impediu os fabricantes de produtos genéricos
de utilizarem o seu direito de beneficiar dos ditos
resultados não encontra justificação na proteção
legítima de um investimento integrado na concor-
rência baseada no mérito, visto que, por força da
Diretiva $65 / 65$, o AZ tinha deixado precisamente
de gozar do direito exclusivo de explorar os resulta-
dos desses ensaios ${ }^{25}$.

A AstraZeneca argumentou, por sua vez, que o simples exercício de um direito, conferido pelo Direito da União Europeia, não poderia ser incompatível com a noção de "concorrência pelos méritos". Esse argumento não prosperou, dado que o TJUE afirmou que "os abusos de posição dominante consistem, na maioria dos casos, em comportamentos que seriam lícitos à luz de outros ramos do direito que não o Direito da Concorrência" ${ }^{26}$. O TJUE entendeu que essa estratégia da empresa AstraZeneca tinha como objetivo excluir os fabricantes genéricos, e isso não estava de acordo com a sua responsabilidade especial de empresa dominante.

Em síntese, foi reiterado o entendimento segundo o qual uma empresa, em posição dominante, não pode instrumentalizar procedimentos com intuito único e exclusivo de impedir ou tornar mais difícil a entrada de concorrentes no mercado. Em outras palavras, a empresa em posição dominante somente pode excluir os seus competidores ou potenciais competidores se houver justificações econômicas objetivas. Caso contrário, tal estratégia não será entendida como uma concorrência baseada nos méritos.

25 TRIBUNAL DE JUSTIÇA DA UNIÃO EUROPEIA. Processo n. C-457/10P, AstraZeneca/Comissão, 6 déc. 2012. Disponível em: http://curia.europa.eu/juris/document/document.jsf?text=\&doci $\mathrm{d}=131490$ \&pageIndex $=0$ \&doclang $=$ PT\&mode $=1$ st\&dir $=\&$ occ $=$ fir st\&part=1\&cid=342734. Acesso em: 20 dez. 2019. \$131.

26 TRIBUNAL DE JUSTIÇA DA UNIÃO EUROPEIA. Processo n. C-457/10P, AstraZeneca/Comissão, 6 déc. 2012. Disponível em: http://curia.europa.eu/juris/document/document.jsf?text $=\&$ doci $\mathrm{d}=131490$ \&pageIndex $=0 \&$ doclang $=$ PT $\&$ mode $=1$ st $\&$ dir $=\&$ occ $=$ fir st\&part=1\&cid=342734. Acesso em: 20 dez. 2019. \$132. 
A análise do Tribunal de Justiça da União Europeia permite obter as seguintes conclusões: (i) os abusos de posição dominante têm uma aparência a priori de legalidade; (ii) a aplicação do Direito da Concorrência pode revelar amplitude mais real dos prejuízos ao bem-estar de prática de empresas no mercado de alta tecnologia; e (iii) a incidência de um ramo do direito não afasta a incidência do Direito da Concorrência, se forem observados os critérios legais.

\section{Decisão do caso Servier}

Em 2014, a Comissão Europeia condenou Servier, empresa francesa, e cinco fabricantes de medicamentos genéricos - Niche/Unichen, Matrix, Teva, Krka e Lupin - a pagarem multa de 427,7 milhões de euros. $\mathrm{Na}$ ocasião, entendeu-se que a autocomposição processual foi instrumentalizada para impedir que competidores entrassem no mercado farmacêutico europeu.

A autocomposição processual é normalmente vista como benéfica e vantajosa forma de resolver problemas no Poder Judiciário. Quando as partes transigem sobre o objeto da lide, evita-se que o processo se prolongue por maior período, de modo que facilita uma solução a qual satisfaça igualmente os envolvidos. Todavia, a existência de relação de hipossuficiência e/ou de assimetria econômica e de informações entre as partes, por exemplo, pode ser utilizada como meio para finalidades ilícitas.

O caso em análise também é importante porque colocou em evidência a possibilidade de se avaliar a abusividade na aquisição de determinada tecnologia (4.1). Esse elemento foi essencial para a aplicação dos artigos 101 e 102 (TFUE) para punir as empresas (4.2).

\subsection{Aquisição abusiva de tecnologia}

De acordo com a Comissão Europeia, a empresa Servier detinha poder de mercado importante sobre o mercado da molécula de perindopril, usada em medicamentos para hipertensão. Esse entendimento decorre do fato de nenhum desses medicamentos, a não ser os genéricos, ser suscetível a reduzir as vendas ou os preços praticados pela dita empresa. Contudo, a principal patente de Servier havia expirado em 2003, restando, apenas, patentes secundárias, relativas aos procedimen- tos e à forma do produto. Essa proteção, menos eleva$\mathrm{da}$, tornou o mercado mais propício às empresas produtoras de genéricos, que se preparavam para competir com Servier.

As empresas de genéricos atuavam em duas frentes para superar os últimos entraves para entrar no mercado: (i) ter acesso aos produtos sem patente; e (ii) contestar patentes da Servier em que os produtores de genéricos acreditavam e que os bloqueavam indevidamente. Em 2004, a Servier adquiriu a tecnologia mais avançada do setor, o que obrigou o abandono de vários projetos desenvolvidos pelos fabricantes de genéricos. Foi impossível ter acesso aos produtos sem patentes, dada a impossibilidade de utilizar a referida tecnologia na produção dos referidos medicamentos. Houve, assim, o adiamento da entrada dos genéricos no mercado.

A própria Servier, por sua vez, nunca utilizou a referida tecnologia, o que contribuiu para compreender a referida aquisição como mecanismo de defesa concorrencial da empresa. Restou às empresas de genéricos, portanto, discutir judicialmente as patentes da Servier, que elas acreditavam bloquear indevidamente a sua entrada. É justamente sobre a solução dos conflitos dessas judicializações que recaiu a aplicação das normas de Direito da Concorrência da União Europeia.

\subsection{Aplicação dos artigos 101 e 102 do TFUE}

A Comissão Europeia constatou que, de 2005 a 2007, praticamente toda vez que um produtor de genéricos ajuizava ações, as partes realizavam autocomposição para extinguir o processo. Portanto, a transação processual não versava simplesmente sobre uma solução acerca de um litígio sobre direitos de propriedade intelectual. $\mathrm{Na}$ realidade, acordava-se a abstenção das empresas de produtos genéricos no mercado, em troca do repasse de parte dos lucros da Servier. De acordo com o então vice-presidente da Comissão Europeia, Joaquin Almunia:

Servier recorreu a uma estratégia que consistia em comprar sistematicamente toda ameaça de concorrência, a fim de garantir que ela continuaria afastada do mercado. Um tal comportamento é manifestadamente anticoncorrencial e abusivo. As empresas concorrentes não podem acordar entre si para dividir os mercados ou os lucros de um mercado, no lugar de concorrer entre si, mesmo que tais acordos tomem a forma de soluções amigáveis em matéria de patente. Esse tipo de prática traz danos diretos aos pacientes, aos sistemas de saúde nacional e aos 
contribuintes. As empresas farmacêuticas deveriam concentrar seus esforços sob a inovação e a concorrência no lugar de tentar extrair lucros suplementares dos pacientes ${ }^{27}$.

A Comissão Europeia entendeu que é legítimo e desejável solicitar patentes, transferir tecnologia e promover a autocomposição dos conflitos. Todavia, no caso Servier, constatou-se que houve utilização abusiva desses institutos, uma vez que se impediu o desenvolvimento de tecnologia dos concorrentes e desencorajou, de maneira ilícita, a entrada de potenciais competidores que iam colocar no mercado medicamentos mais baratos. O resultado dessas práticas foi o prejuízo da concorrência pelos próprios méritos, o que permitiu a aplicação dos artigos 101 e 102, do TFUE.

$\mathrm{O}$ art. 102 foi aplicado aos abusos de posição dominante decorrente da estratégia da Servier de impedir o desenvolvimento da tecnologia concorrente. Já o art. 101, foi aplicado em cada transação processual com efeitos anticompetitivos. De acordo com a Comissão Europeia,

um fabricante de genéricos reconheceu que ele “comprava mercado do périndopril". Um outro insistiu no fato que "toda solução amigável podia acontecer por somas significativas", que ele qualificava igualmente de "grande soma de dinheiro". No total, as transferências de dinheiro aos fabricantes de genéricos alcançaram vários milhões de euros. Em um certo caso, Servier ofereceu a um fabricante de genéricos uma licença a 7 mercados nacionais; em contrapartida, este aceitou se "sacrificar" em todos os outros mercados da União Europeia e parar os esforços para lançar o seu périndopril nesses países. Servier obteve assim a segurança que os fabricantes de genéricos restariam afastados dos mercados nacionais e se absteriam de todo recurso jurisdicional durante toda a duração dos acordos ${ }^{28}$.

Entende-se que a decisão do caso Servier coloca em evidência a possibilidade de uma empresa em posição dominante adquirir uma determinada tecnologia com a única finalidade de impedir a entrada de competidores

\footnotetext{
${ }^{27}$ COMISSÃO EUROPEIA. Ententes et abus de position dominante: la Commission inflige des amendes à Servier et à cinq fabricants de génériques pour avoir freiné l'entrée sur le marché de versions moins chères d'un médicament cardiovasculaire. Communiqué de presse, 9 jul. 2014. Disponível em: https://ec.europa.eu/commission/presscorner/detail/fr/IP_14_799. Acesso em: 02 jan. 2020.

28 COMISSÃO EUROPEIA. Ententes et abus de position dominante: la Commission inflige des amendes à Servier et à cinq fabricants de génériques pour avoir freiné l'entrée sur le marché de versions moins chères d'un médicament cardiovasculaire. Communiqué de presse, 9 jul. 2014. Disponível em: https://ec.europa.eu/commission/presscorner/detail/fr/IP_14_799. Acesso em: 02 jan. 2020.
}

no mercado. Importa destacar a dificuldade de se provar que a compra de uma tecnologia, por si só, seja considerada anticoncorrencial. Contudo, o caso em espécie permite entender que ela pode vir conjugada com outros comportamentos abusivos, que acabam impedindo a entrada de novos produtos (melhores ou mais baratos) e novos competidores.

\section{Decisão do caso Buprenorfina}

A experiência da Autoridade da Concorrência francesa no que diz respeito à aplicação do Direito da Concorrência nos casos de depreciação dos concorrentes pode ser compreendida como um importante aporte para a proteção da inovação. O mercado dos medicamentos se apresenta novamente como sendo um locus no qual as empresas detentoras de direitos de propriedade intelectual atentam à concorrência pelos méritos, afastando abusivamente seus concorrentes.

O caso Buprenorfina descortinou os efeitos da depreciação dos genéricos, promovida pelas empresas detentoras das patentes principais, na entrada daqueles no mercado em questão. A amplitude do fechamento do mercado e o atentado ao bem-estar do consumidor foram avaliados de maneira mais realista, dada a incorporação dos argumentos decorrentes da modernização do Direito da Concorrência da União Europeia. Portanto, essa decisão também contribuiu para a sistematização do modelo europeu de proteção da inovação pela aplicação dessas normas.

O caso Buprenorfina enquadra-se, também, no espírito do inquérito do setor efetuado pela direção geral da concorrência da Comissão Europeia no domínio farmacêutico ${ }^{29}$. Com os dados sobre o mercado relevante apresentados no referido inquérito, a Autoridade da Concorrência francesa apoiou-se na proibição de acordos e abusos de posição dominante para sancionar as fraudes e açambarcamentos no mercado de medicamentos (5.1). Assim, as estratégias, para impedir a entrada de genéricos no mercado, possibilitaram uma revisão da intervenção concorrencial nos casos de depreciação dos concorrentes (5.2).

29 COMISSÃO EUROPEIA. Comunicação da Comissão Europeia: síntese do relatório sobre o inquérito ao setor farmacêutico. 8 jul. 2009. Disponível em: http://ec.europa.eu/competition/sectors/pharmaceuticals/inquiry/communication_pt.pdf. Acesso em: 24 mar. 2019. 


\subsection{Estratégia contra os genéricos}

No parecer n. 13-A-24 de 29 de dezembro de 2013 da Autoridade da Concorrência francesa, relativo ao funcionamento da concorrência no setor de distribuição de remédios de utilização humana, a Autoridade da Concorrência francesa expôs que as práticas de depreciação dos concorrentes tomam diversas formas. Elas ocorrem nos lugares de fabricação afirmando que os medicamentos genéricos não têm eficácia, apresentam efeitos nocivos ou ainda não possuem bioequivalência. Desde 2003, o Conselho da Concorrência analisa esse tipo de caso no mercado de medicamentos ${ }^{30}$.

A Comissão Europeia não tem condenações pela depreciação dos concorrentes. Entretanto, a Autoridade da Concorrência francesa já acumula alguns casos condenados. Isso demonstra o esforço em promover a concorrência pelos méritos no mercado dos medicamentos, notadamente no que concerne aos entraves a entrada dos genéricos. Entre eles, o caso mais emblemático é AstraZeneca, mas outros também merecem ser destacados como o caso Lundbeck; Johnson \& Johnson; Norvatis; e Fentenyl.

A Autoridade da Concorrência francesa sancionou o laboratório Schering-Plought no montante de 15,3 milhões de euros, pelo fato de a empresa ter utilizado estratégia abusiva para impedir a chegada do genérico do Subutex (molécula de buprenorfina). Esse poder econômico privado se revela com a notoriedade do laboratório, sua influência diante os que o prescrevem e

30 CONSÉIL DE LA CONCURRENCE. Processo n. 03-D-35. Sandoz-Norvatis Pharma. 24 jul. 2003. Disponível em: https://www.autoritedelaconcurrence.fr/sites/default/files/commitments//03d35. pdf. Acesso em: 01 jun. 2019. No que diz respeito as demais investigações de condutas ilícitas contra os genéricos na França, ver: PRIETO, Catherine. Ventes liées: la Cour de cassation statue sur l'imbrication de techniques susceptible de rendre acceptables des prix élevés... ou d'évincer des concurrents (Novartis). Concurrences, n. 4, p. 79-82, 2005.; PRIETO, Catherine. Abus de position dominante par dénigrement dans l'offre de contracter. Revue des contrats, n. 2, 1 jul. 2014. Disponível em: https://www.lextenso.fr/. Acesso em: 20 jun. 2019. WACHMANN, Anne. La Cour de cassation approuve l'analyse de la Cour d'appel de Paris concernant l'absence de prix prédateurs (GlaxoSmithKline). Concurrences, n. 2, p. 117-118, 2009.; SIBONY, Anne-Lise. La Cour d'appel de Paris réforme la décision condamnant Glaxo pour une pratique de prix prédateurs évinçant les fabricants de médicaments génériques du marché des hopitaux (GlaxoSmithKline). Concurrences, n. 2, p. 118, 2008.; SIBONY, AnneLise. Pratiques de dénigrement: l'autorité de la concurrence indique que des pratiques de dénigrement peuvent constituer un abus à condition qu'un lien soit établi entre la position dominante et le dénigrement (fourniture d'électricité). Concurrences, n. 2, p. 126-127, 2009. a força da sua rede comercial. Esse medicamento é utilizado para o tratamento da dependência aos opiáceos dos pacientes toxicômanos e pertence ao laboratório Reckitt Benckiser Group, o qual disponibilizou a Schering-Plought os direitos de comercialização exclusivos na França ${ }^{31}$.

A autoridade imputou-lhe dois abusos de posição dominante: a prática de depreciação do genérico do Subutex e a implementação de descontos de fidelização em favor de certas farmácias. A autoridade não encontrou maiores problemas para considerar os descontos de exclusividade abusivos, pois eram constituídos por descontos quantitativos, prazos de pagamentos e descontos para o pagamento propostos aos farmacêuti$\cos ^{32}$. Portanto, a presente análise vai se limitar ao primeiro abuso de posição dominante.

O órgão francês desenvolveu uma jurisprudência que permite sancionar práticas de depreciação dos concorrentes e muitos casos já foram punidos, diferentemente da experiência da Comissão Europeia ${ }^{33}$. Entretanto, apenas com a condenação de Sanofi-Aventis, que

31 AUTORITÉ DE LA CONCURRENCE. Comuniqués. L'Autorité de la concurrence sanctionne à hauteur de 15,3 millions d'euros le laboratoire pharmaceutique Schering-Plough pour avoir entravé l'arrivée du générique de son médicament princeps Subutex®. 19 dez. 2013. Disponível em: https://www.autoritedelaconcurrence. $\mathrm{fr} / \mathrm{fr} /$ communiques-de-presse/lautorite-sanctionne-hauteur-de153-millions-deuros-le-laboratoire. Acesso em: 28 dez. 2020.

32 WACHSMANN, Anne; ZACHARIE, Nicolas. L'Autorité de la concurrence sanctionne un laboratoire pharmaceutique pour des pratiques de dénigrement et de rabais de fidélité accordés à des pharmaciens ayant eu pour objectif d'entraver l'entrée sur le marché d'un concurrent générique (Aut. Conc., 18 décembre 2013, décision n. 13-D-21 relative à des pratiques mises en œuvre sur le marché français de la buprénorphine haut dosage commercialisée en ville). Concurrences, n. 1, 2014. p. 80.

33 PRIETO, Catherine. Abus d'exclusion: la Cour de cassation rejette le pourvoi de France Telecom relatif à deux abus constitués par des conditions restrictives d'accès à des infrastructures essentielles ayant entravé des concurrents sur le marché d'accès au haut débit (France Telecom). Concurrences, n. 1, p. 122, 2008.; SIBONY, AnneLise. Pratiques de dénigrement: l'autorité de la concurrence indique que des pratiques de dénigrement peuvent constituer un abus à condition qu'un lien soit établi entre la position dominante et le dénigrement (fourniture d'électricité). Concurrences, n. 2, p. 126-127, 2009.; MARTY, Frédéric. Éviction anticoncurrentielle: l'autorité de la concurrence demande un supplément d'instruction pour évaluer les risques de préemption du marché de la diffusion de contenus audiovisuels sur la fibre optique au moyen de clauses d'exclusivité (Secteur de la télévision payante). Concurrences, n. 1, p. 110-113, 2011.; e MASCRET, Caroline. Les enseignements de l'autorité de la concurrence en matière d'abus de position dominante pour des pratiques visant à retarder l'entreée sur le marché d'un médicament générique. Petites affiches, n. 221, Paris, 5 nov. 2014. 
a autoridade começou a aplicar essa jurisprudência a um laboratório farmacêutico. No caso em questão, o quadro de análise consagrado na jurisprudência é dividido em três etapas: (i) verificar a existência da depreciação; (ii) examinar se o discurso é capaz de influenciar a estrutura de mercado; e (iii) avaliar a relação de causalidade entre a dominação da empresa em questão e a prática de depreciação.

A primeira etapa é verificar se o discurso comercial sustentado difunde informações não verificadas. Muitos dados factuais permitiram identificar que Schering-Plough, antes e depois da entrada do genérico no mercado, colocou em questão a qualidade do produto, sem que seu discurso fosse sustentado pela ordem médica ou científica.

A segunda etapa é examinar os efeitos esperados ou reais do discurso no mercado. Isso ficou claro porque Schering-Plough mantinha $90 \%$ da parte de mercado e ainda foi constatada uma proporção não habitual de prescrições de médicos, os quais indicavam a ausência de substituibilidade entre os medicamentos.

A terceira etapa é estabelecer um vínculo entre a posição dominante da empresa e a prática de depreciação. De acordo com o órgão francês responsável pela concorrência,

existe, portanto, uma relação direta entre a posição dominante de Schering-Plough e a prática em questão: é essa posição dominante, e notadamente a notoriedade e a confiança resultantes, cuja Schering-Ploug era a única a deter, que permitiu à empresa de dar sua plena eficácia à estratégia consistente a denegrir Buprenorfina Arrow ${ }^{\circledR}$ em benefício de seu próprio medicamento ${ }^{34}$.

Em síntese, a empresa que detinha os direitos de propriedade intelectual do medicamento principal utilizou seu poder de mercado para sair de seu papel substituindo de facto as autoridades de saúde responsáveis ${ }^{35}$. Esse comportamento abusivo foi então punido severamente pela Autoridade da Concorrência francesa.

\footnotetext{
34 AUTORITÉ DE LA CONCURRENCE. Processo n. 13-D-21. Relative à des pratiques mises en œuvre sur le marché français de la buprénorphine haut dosage commercialisée en ville. 18 dez. 2013. Disponível em: https://www.autoritedelaconcurrence.fr/sites/default/files/commitments//13d21.pdf. Acesso em: 28 dez. 2020. \$ 398.

35 MARTY, Frédéric. L'Autorité de la concurrence prononce une amende de plus de quarante millions d'euros à l'encontre d'un laboratoire pharmaceutique pour avoir entravé l'entrée sur le marché de médicaments génériques par l'intermédiaire de pratiques de dénigrement. Concurrences, n. 3, p. 82-85, 2013. p. 85.
}

\subsection{Contribuição da Autoridade da Concorrência francesa}

O caso Buprenorfina se insere dentro de um corpus decisório mais largo da Autoridade da Concorrência francesa para sancionar a depreciação dos concorrentes e contribuiu para a consolidação dos limites à liberdade da empresa em sua posição dominante no mercado. Constata-se, assim, uma outra aplicação do Direito da Concorrência para proteger a inovação.

No que concerne à indústria farmacêutica, o fechamento artificial do mercado é uma estratégia normalmente utilizada para afastar a entrada dos genéricos, e isso restringe a escolha dos consumidores, que ficam aprisionados artificialmente em uma solução mais cara: os medicamentos principais. Dessa maneira, a aplicação do Direito da Concorrência nos casos de depreciação reforça a efetividade desse tipo de intervenção nos abusos praticados pelas empresas de alta tecnologia. Entretanto, é importante salientar que o objetivo do Direito da Concorrência não é de discutir os méritos terapêuticos ou a validade das patentes, mas unicamente de analisar as práticas que deturpam os valores da bioequivalência e da substituição ${ }^{36}$.

A prática de depreciação dos concorrentes e os descontos, sem contrapartida econômica justificada, fazem parte de uma estratégia de Schering-Plough para impedir o acesso do mercado ao genérico e distorcer a concorrência pelos méritos. Por consequência, os efeitos dessa estratégia devem ser avaliados não apenas em termos de aumento dos preços para os consumidores finais, mas também no que diz respeito à difusão dos genéricos.

A punição pela depreciação dos concorrentes é normalmente compreendida como uma prática desleal. A originalidade e importância da Autoridade da Concorrência francesa decorrem do fato dela reforçar a complementaridade entre esses ramos do Direito, nos casos envolvendo práticas de empresa em posição dominante.

Um outro ponto de interesse dessa decisão é reforçar a preocupação já estabelecida com a decisão Sanofi-Aventis, notadamente no que diz respeito ao equilíbrio entre a severidade da sanção e a complexidade das estratégias predatórias. Isso significa que os efeitos des-

36 PRIETO, Catherine. Abus de position dominante par dénigrement dans l'offre de contracter. Revue des contrats, n. 2, 1 jul. 2014. Disponível em: https://www.lextenso.fr/. Acesso em: 20 jun. 2019. 
sa natureza de estratégia não se restringem apenas ao mercado no qual ela se desenvolve. Ou seja, a estratégia da empresa em questão passa um sinal do grau de sua agressividade no mercado, caso entrantes potenciais desejem ingressar na competição ${ }^{37}$. Esse caso ilustra, portanto, como práticas desleais podem tomar a forma de abuso de posição dominante.

\section{Considerações finais}

Um dos principais aspectos da originalidade do modelo europeu é a preocupação das autoridades responsáveis pela concorrência com o controle de condutas. $\mathrm{O}$ vasto corpo decisório desse eixo de aplicação do Direito da Concorrência reforça essa percepção. O presente trabalho, entretanto, permitiu ir além dessa constatação e evidenciou que esse eixo tem sido aplicado com intuito de promover a inovação em setores caracterizados pela presença de direitos de propriedade intelectual, como a indústria farmacêutica. Essa é uma importante originalidade da experiência normativa analisada.

Dessa maneira, o primeiro aporte da pesquisa refere-se à contribuição para a sistematização das decisões europeias sobre a proteção da inovação pela aplicação das normas concorrenciais. Entender a mencionada originalidade também possibilitou lançar um novo olhar nas experiências nacionais dos países membros da União Europeia. Por essa razão, a decisão francesa no caso Buprenorfina é fundamental para entender que o processo de harmonização de aplicação do Direito da União Europeia tem avançado de maneira consistente. $\mathrm{Na}$ realidade, a decisão francesa se insere no contexto promovido pelas autoridades europeias, mas vai além, pois consolida um quadro de análise para punição, pela aplicação de normas concorrenciais, da depreciação de concorrentes.

O segundo aporte da pesquisa foi auxiliar na compreensão da utilização dos quadros de análise empregados pelas autoridades europeias. Essa técnica garante maior segurança jurídica, tendo em vista os ganhos de previsibilidade e de transparência na aplicação das nor-

\footnotetext{
37 MARTY, Frédéric. L'Autorité de la concurrence prononce une amende de plus de quarante millions d'euros à l'encontre d'un laboratoire pharmaceutique pour avoir entravé l'entrée sur le marché de médicaments génériques par l'intermédiaire de pratiques de dénigrement. Concurrences, n. 3, p. 82-85, 2013. p. 82.
}

mas de Direito da Concorrência. Além disso, a adoção da metodologia dos quadros de análise também pode garantir objetividade na adequação dos requisitos para punição das infrações clássicas às necessidades contemporâneas da economia. A análise da metodologia europeia permite concluir que a Teoria das Infraestruturas Essenciais não é obrigatoriamente necessária para resolver as questões concorrenciais envolvendo direitos de propriedade intelectual.

O terceiro aporte da pesquisa foi indicar que as autoridades responsáveis por conceder os direitos de propriedade intelectual podem encontrar significativas dificuldades na avaliação da abusividade de estratégias de detentores de patentes. Entretanto, a incorporação da preocupação com a proteção da inovação na aplicação do Direito da Concorrência revela um papel renovado dos órgãos de defesa da concorrência. Estes podem contribuir, de maneira mais efetiva, para garantir uma estrutura concorrencial mais competitiva, viabilizando não apenas inovações de ruptura, mas também condições adequadas para pequenas e médias empresas se apresentarem como competidoras das empresas em posição dominante.

\section{Referências}

AHNER, Francis. La Cour de Justice au diapason? L'interprétation du règlement (CE) n. 469/2009 concernant le certificat complémentaire de protection pour les médicaments par la Cour de Justice de l'Union Européenne. In: GEIGER, Christophe; RODÀ, Caroline (coord.). Le droit de la propriété intellectuelle dans un monde globalisé: mélanges en l'honneur du Professeur Joanna Schmidt-Szalewski. Paris: Lexis Nexis, 2013. p. 1-16.

AUTORITÉ DE LA CONCURRENCE. Comuniqués. L'Autorité de la concurrence sanctionne à hauteur de 15,3 millions d'euros le laboratoire pharmaceutique Schering-Plough pour avoir entravé l'arrivée du générique de son médicament princeps Subutex ${ }^{\circledR} .19$ dez. 2013. Disponível em: https://www.autoritedelaconcurrence.fr/fr/communiques-de-presse/lautorite-sanctionne-hauteur-de-153-millions-deuros-le-laboratoire. Acesso em: 28 dez. 2020.

AUTORITÉ DE LA CONCURRENCE. Processo $n$. 13-D-21. Relative à des pratiques mises en œuvre sur le marché français de la buprénorphine haut dosage 
commercialisée en ville. 18 dez. 2013. Disponível em: https://www.autoritedelaconcurrence.fr/sites/default/ files/commitments//13d21.pdf. Acesso em: 28 dez. 2020.

COMISSÃO EUROPEIA. Ententes et abus de position dominante: la Commission inflige des amendes à Servier et à cinq fabricants de génériques pour avoir freiné l'entrée sur le marché de versions moins chères d'un médicament cardiovasculaire. Communiqué de presse, 9 jul. 2014. Disponível em: https://ec.europa.eu/commission/presscorner/detail/fr/IP_14_799. Acesso em: 02 jan. 2020.

COMISSÃO EUROPEIA. Comunicação da Comissão Europeia: síntese do relatório sobre o inquérito ao setor farmacêutico. 8 jul. 2009. Disponível em: http:// ec.europa.eu/competition/sectors/pharmaceuticals/ inquiry/communication_pt.pdf. Acesso em: 24 mar. 2019.

CONSELHO DAS COMUNIDADES EUROPEIAS. Regulamento (CEE) n. 1768/92 do Conselho de 18 de junho de 1992 relativo à criação de um certificado complementar de proteção para medicamentos. Jornal Oficial das Comunidades Europeias, 18 jun. 1992. Disponível em: https:// eur-lex.europa.eu/legal-content/PT/TXT/PD $\mathrm{F} /$ ?uri=CELEX:31992R1768\&from $=$ PT. Acesso em: 20 dez. 2019.

CONSÉIL DE LA CONCURRENCE. Processo $n$. 03-D-35. Sandoz-Norvatis Pharma. 24 jul. 2003. Disponível em: https://www.autoritedelaconcurrence.fr/ sites/default/files/commitments//03d35.pdf. Acesso em: 01 jun. 2019.

DEZOBRY, Guillaume. Facilités essentielles. In: BAZEX, Michel et al. (dir.). Dictionnaire des régulations. Paris: Lexis Nexis, 2016.

DIZ, Jamile Bergamaschine Mata; JAEGER JÚNIOR, Augusto. Por uma teoria jurídica da integração regional: a inter-relação direito interno, direito internacional público e direito da integração. Revista de Direito Internacional, Brasilia, v. 12, n. 2, p. 138-158, 2015. Disponível em: https://www.publicacoesacademicas.uniceub.br/ rdi/article/view/3710/pdf. Acesso em: 30 jul. 2021.

DOSI, Giovani; MARENGO, Luigi; PASQUALI, Corrado. How much should society fuel the greed of innovators? On the relations between appropriability, opportunities and rates of innovation. Research Policy, v. 35, n. 8, p. 1110-1121, 2006. Disponível em: https://www.
econstor.eu/bitstream/10419/89527/1/51846122X. pdf. Acesso em: 01 jun. 2019.

FERRAZ, Daniel Amin. A jurisprudência norteamericana e europeia sobre os acordos horizontais e verticais: substrato para análise da matéria no Brasil. Revista de Direito Internacional, Brasília, v. 10, n. 1, p. 232-242, 2013. Disponível em: https://www.publicacoesacademicas. uniceub.br/rdi/article/view/2427/pdf. Acesso em: 30 jul. 2021.

FOX, Eleanor. Economic development, poverty, and antitrust: the other path. Southwestern Journal of Law and Trade in the Americas, v. 13, p. 101-125, 2007. Disponível em: https://papers.ssrn.com/sol3/papers. cfm?abstract_id=1002637. Acesso em: 16 abr. 2018.

FOX, Eleanor. A antitrust fable: a tale of predation. Concurrences, n. 3, p. 1-2, 2008.

HILTY, Reto M. La limitation de la propriété intellectuelle comme moyen d'encourager l'innovation. In: GEIGER, Christophe; RODÀ, Caroline (coord.). Le droit de la propriété intellectuelle dans un monde globalisé: mélanges en l'honneur du Professeur Joanna SchmidtSzalewski. Paris: Lexis Nexis, 2013. p. 201-220.

IDOT, Laurence. Réflexions sur la convergence des droits de la concurrence. Concurrences, n. 4, 2012.

JAEGER JÚNIOR, Augusto; JORGE, Mariana Sebalhos. O caso interl: o impacto na evolução da teoria dos efeitos no direito da concorrência da União Europeia. Revista de Direito Internacional, Brasília, v. 16, n. 1, p. 269287, 2019. Disponível em: https://www.publicacoesacademicas.uniceub.br/rdi/article/view/5655/pdf. Acesso em: 30 jul. 2021.

KOVAR, Robert. Les innovations abusives: à la croisée des droits de propriété intellectuelle et de la concurrence. Droits de propriété intellectuelle: liber amicorum Georges Bonet. Paris: Lexis Nexis Litec, 2010.

LEURQUIN, Pablo. A importância do caso Microsoft na modernização do Direito da Concorrência da União Europeia. In: ARAÚJO, Francisco Marcos de; SALDANHA, Ana Clara Bezerra de Góis; AMARAL, Maria Teodora Rocha Maia (orgs.). O direito e as novas tecnologias na sociedade da informação. São Paulo: Dialética, 2021. No prelo.

LEURQUIN, Pablo. Proteção da inovação pelo direito brasileiro da concorrência e diálogo com o direito da União Europeia. 2018. Tese (Doutorado em Direito) - Universidade Fe- 
deral de Minas Gerais, Belo Horizonte; Université Paris 1 Panthéon-Sorbonne, Paris, 2018.

LEURQUIN, Pablo. Proteção da inovação pelo direito da concorrência. Belo Horizonte: Expert, 2021.

MARTY, Frédéric. Éviction anticoncurrentielle: l'autorité de la concurrence demande un supplément d'instruction pour évaluer les risques de préemption du marché de la diffusion de contenus audiovisuels sur la fibre optique au moyen de clauses d'exclusivité (Secteur de la télévision payante). Concurrences, n. 1, p. 110-113, 2011.

MARTY, Frédéric. L'Autorité de la concurrence prononce une amende de plus de quarante millions d'euros à l'encontre d'un laboratoire pharmaceutique pour avoir entravé l'entrée sur le marché de médicaments génériques par l'intermédiaire de pratiques de dénigrement. Concurrences, n. 3, p. 82-85, 2013.

MASCRET, Caroline. Les enseignements de l'autorité de la concurrence en matière d'abus de position dominante pour des pratiques visant à retarder l'entreée sur le marché d'un médicament générique. Petites affiches, $\mathrm{n}$. 221, Paris, 5 nov. 2014.

PRIETO, Catherine. Abus de position dominante par dénigrement dans l'offre de contracter. Revue des contrats, n. 2, 1 jul. 2014. Disponível em: https://www.lextenso. fr/. Acesso em: 20 jun. 2019.

PRIETO, Catherine. Abus d'exclusion: la Cour de cassation rejette le pourvoi de France Telecom relatif à deux abus constitués par des conditions restrictives d'accès à des infrastructures essentielles ayant entravé des concurrents sur le marché d'accès au haut débit (France Telecom). Concurrences, n. 1, p. 122, 2008.

PRIETO, Catherine. Ventes liées: la Cour de cassation statue sur l'imbrication de techniques susceptible de rendre acceptables des prix élevés... ou d'évincer des concurrents (Novartis). Concurrences, n. 4, p. 79-82, 2005.

PRIETO, Catherine; BOSCO, David. Droit européen de la concurrence: ententes et abus de position dominante. Bruxelas: Bruylant, 2013.

SCHUARTZ, Luis Fernando. O direito da concorrência e seus fundamentos. In: POSSAS, Mario Luiz (coord.). Ensaios sobre economia e direito da concorrência. São Paulo: Singular, 2002. p. 33-74.

SEGALA, Michele M.; GREGORI, Isabel Christine S. de. Os reflexos da proteção internacional da proprie- dade intelectual para o desenvolvimento interno: uma análise sobre o sistema patentário brasileiro e a transferência de tecnologia. Revista de Direito Internacional, Brasília, v. 1, n. 2, p. 524-535, 2017. Disponível em: https://www.publicacoesacademicas.uniceub.br/rdi/ article/view/4678/pdf. Acesso em: 30 jul. 2021.

SIBONY, Anne-Lise. Définition du marché pertinent utilisation abusive - Procédures relatives aux certificats complémentaires de protection pour les médicaments procédures d'autorisation de mise sur le marché: la Cour de Justice de l'UE sanctionne définitivement l'utilisation abusive de procédures réglementaires pour prévenir ou retarder l'arrivée des génériques sur le marché (CJUE, 6 décembre 2012, AstraZeneca AB et AstraZeneca c/ Commission, aff. C-457/10 P). Concurrences, n. 1, p. 7881, 2013.

SIBONY, Anne-Lise. La Cour d'appel de Paris réforme la décision condamnant Glaxo pour une pratique de prix prédateurs évinçant les fabricants de médicaments génériques du marché des hopitaux (GlaxoSmithKline). Concurrences, n. 2, p. 118, 2008.

SIBONY, Anne-Lise. Pratiques de dénigrement: l'autorité de la concurrence indique que des pratiques de dénigrement peuvent constituer un abus à condition qu'un lien soit établi entre la position dominante et le dénigrement (fourniture d'électricité). Concurrences, n. 2, p. 126-127, 2009.

SILVA, Tatianna Mello Pereira da. Acordo TRIPS: onesize-fits-all? Revista de Direito Internacional, Brasília, v. 10, n. 1, p. 57-70, 2013. Disponível em: https://www.publicacoesacademicas.uniceub.br/rdi/article/view/1987/ pdf. Acesso em: 30 jul. 2021.

STIGLITZ, Joseph E. O preço da desigualdade. Lisboa: Bertrand Editor, 2013.

TRIBUNAL DE JUSTIÇA DA UNIÃO EUROPEIA. Processo n. C-457/10P, AstraZeneca/Comissão, 6 déc. 2012. Disponível em: http://curia.europa.eu/juris/document $/$ document.jsf?text $=\&$ docid $=131490 \&$ pageInd ex $=0 \&$ doclang $=$ PT \&mode $=1$ st $\&$ dir $=\&$ occ $=$ first\&part $=1 \&$ cid $=342734$. Acesso em: 20 dez. 2019.

WACHMANN, Anne. Le Conseil de la Concurrence condamne lourdement un laboratoire pharmaceutique pour avoir freiné le développement des médicaments génériques à l'hôpital par une pratique de prix prédateur (GlaxoSmithKline). Concurrences, n. 2, p. 110-115, 2007. 
WACHMANN, Anne. La Cour de cassation approuve l'analyse de la Cour d'appel de Paris concernant l'absence de prix prédateurs (GlaxoSmithKline). Concurrences, n. 2, p. 117-118, 2009.

WACHSMANN, Anne; ZACHARIE, Nicolas. L'Autorité de la concurrence sanctionne un laboratoire pharmaceutique pour des pratiques de dénigrement et de rabais de fidélité accordés à des pharmaciens ayant eu pour objectif d'entraver l'entrée sur le marché d'un concurrent générique (Aut. Conc., 18 décembre 2013, décision n. 13-D-21 relative à des pratiques mises en œuvre sur le marché français de la buprénorphine haut dosage commercialisée en ville). Concurrences, n. 1, 2014.

WU, Tim. Taking innovation seriously: antitrust enforcement if innovation mattered most. Antitrust Law Journal, Washington, v. 78, n. 2, 2012. Disponível em: https://scholarship.law.columbia.edu/faculty_scholarship/1767/. Acesso em: 20 dez. 2019. 
Para publicar na Revista de Direito Internacional, acesse o endereço eletrônico www.rdi.uniceub.br ou www.brazilianjournal.org.

Observe as normas de publicação, para facilitar e agilizar o trabalho de edição. 